\title{
Effect of second molar eruption on efficiency of maxillary first molar distaliza- tion using Carriere distalizer appliance
}

\author{
Ahmed Shawky HASHEM ${ }^{1} \bowtie$ \\ (D) https://orcid.org/0000-0001-8002-7171
}

Submitted: December 04, 2019 - Revised and accepted: May 24, 2020

$\bowtie$ ahmedshawkydent@yahoo.com

How to cite: Hashem AS. Effect of second molar eruption on efficiency of maxillary first molar distalization using Carriere distalizer appliance. Dental Press J Orthod. 2021;26(4):e2119146.

The author reports no commercial, proprietary or financial interest in the products or companies described in this article.

(1) Minia University, Faculty of Dentistry, Department of Orthodontics (Minya, Egypt). 


\section{ABSTRACT}

Introduction: Maxillary molar distalization is a common approach for correcting dental Class II malocclusions.

Objective: This study aimed at comparing the outcomes of maxillary first molar distalization using the Carriere appliance before and after second molar eruption.

Methods: Two groups of patients with dental Class II malocclusions were treated with Carriere distalizer appliance with heavy rectangular mandibular wire and lingual arch for anchorage. Patients of the first group presented unerupted maxillary second molars during the distalization period. In the second group, maxillary second molars were in occlusion on treatment onset. Cone beam computed tomography images were taken at the beginning of treatment and after finishing molar distalization, to compare both groups regarding first molar distalization, intrusion, mesiodistal tipping, buccolingual torquing and rotation, anchorage loss and skeletal changes. Also, the treatment durations were compared.

Results: The mean first molar distalization period in the first group (19.2 \pm 1.6 weeks) was significantly smaller than the second group (23.3 \pm 2.3 weeks). The amount of maxillary first molar distalization was significantly greater, while the amount of rotation was significantly smaller in the first group. No statistically significant differences in the amounts of maxillary first molar intrusion, mesiodistal tipping and buccolingual torquing between both groups was found. Mandibular incisor labiolingual torquing and mandibular first molar mesialization and mesiodistal tipping were significantly greater in the second group.

Conclusions: Maxillary first molar distalization before maxillary second molar eruption is more efficient, with less anchorage loss than after second molar eruption.

Keywords: Maxillary molar distalization. Carriere distalizer. Second molar eruption. 


\section{RESUMO}

Introdução: A distalização do molar superior é uma abordagem comum para a correção da má oclusão de Classe II dentária.

Objetivo: O presente estudo teve como objetivo comparar os resultados da distalização do primeiro molar superior usando o aparelho Carriere antes ou após a erupção do segundo molar.

Métodos: Dois grupos de pacientes com má oclusão de Classe II dentária foram tratados com o distalizador Carriere, com arco inferior retangular espesso e um arco lingual para ancoragem. Os pacientes do primeiro grupo não apresentavam os segundos molares irrompidos durante o período de distalização. No segundo grupo, os segundos molares superiores estavam em oclusão no início do tratamento. Imagens de tomografia computadorizada de feixe cônico foram obtidas no começo do tratamento e após o término da distalização do molar, para comparar ambos os grupos quanto à distalização, intrusão, inclinação mesiodistal, torque vestibulolingual e rotação do primeiro molar, além da perda de ancoragem e mudanças esqueléticas. O tempo de tratamento de ambos os grupos também foi comparado.

Resultados: O tempo médio de distalização do primeiro molar no primeiro grupo (19,2 $\pm 1,6$ semanas) foi significativamente menor que no segundo grupo (23,3 \pm 2,3 semanas). A quantidade de distalização do primeiro molar superior foi significativamente maior e a quantidade de rotação foi significativamente menor no primeiro grupo. Não foram encontradas diferenças significativas entre ambos os grupos quanto à quantidade de intrusão, inclinação mesiodistal e torque vestibulolingual do primeiro molar. O torque vestibulolingual nos incisivos inferiores e a mesialização e inclinação mesiodistal do primeiro molar inferior foram significativamente maiores no segundo grupo.

Conclusões: A distalização do primeiro molar superior feita previamente à erupção do segundo molar superior é mais eficiente, apresentando menor perda de ancoragem do que quando realizada após a erupção do segundo molar.

Palavras-chave: Distalização do molar superior. Distalizador Carriere. Erupção do segundo molar. 


\section{INTRODUCTION}

Dental Class II molar relationship is a frequent malocclusion that can be successfully resolved by means of extractions in at least one arch, ${ }^{1,2}$ using intermaxillary elastics ${ }^{2,3}$ or maxillary molar distalization. ${ }^{4-6}$ Molar distalization has become more prevalent because Class I molar relationship is achieved, a certain amount of space is gained, and tooth extractions can be prevented. ${ }^{6}$

Different types of appliances can be used to distalize maxillary molars including pendulum, ${ }^{4}$ distal jet ${ }^{5}$ headgear ${ }^{7}$ and miniscrews. ${ }^{8}$ The Carriere distalizer (Henry Schein Inc., New York, NY) is a simple fixed appliance used for nonextraction Class II correction, by moving the Class II buccal segment as a block unit into a Class I occlusion. ${ }^{9}$ It was designed to use anchorage from the mandibular arch to create Class I molar and canine relationships.9,10

The distalization phase with the Carriere distalizer appliance commonly precedes full Edgewise appliances bonding, thus increasing adolescent patient's comfort and general experience. ${ }^{11,12}$ The following fixed appliance therapy may be combined with orthodontic or orthopedic maxillary expansion, to refine and detail the occlusion. ${ }^{12}$ 
The type of first molar movement and the treatment timing (before or after second molar eruption) are two factors affecting not only the success, but also the efficiency of molar distalization. ${ }^{13}$

An unerupted maxillary second molar can perform as a fulcrum, resulting in much more evident first molar tipping than when both molars are distalized together. Accordingly, the eruption level of the second molar can have an essential influence on the first molar distalization. ${ }^{14}$

On the contrary, distalization of maxillary first molar alone can result in greater amount of distalization, higher movement rate and less anchorage loss than when both first and second molars are distalized concurrently. ${ }^{15}$ The treatment duration for maxillary first molar distalization increases if the second molar is erupted. ${ }^{16,17}$ Accordingly, the ideal age for maxillary first molar distalization is supposed to be prior to second molar eruption. ${ }^{15-17}$

Other studies concluded that the change of the first molar position and the amount of anchorage preservation are not changed significantly whether the second molar is erupted or not. 4,18,19 The belief that the unerupted second molar represents a fulcrum, increasing the distal tipping of the distalized first molar, is unsupported. ${ }^{13}$ 
Most of the previous studies explaining the effect of maxillary second molar eruption on maxillary first molar distalization used distalizers depending on the upper arch for anchorage, and relied on two-dimensional lateral cephalometric radiographs. ${ }^{13,14,17,19}$ Shortcomings of these two-dimensional radiographs included magnification, geometric distortion, superimposition of anatomical structures and inconsistent head position. ${ }^{20}$ There were no studies, to the best of our knowledge, that used cone beam computed tomography (CBCT) to compare maxillary first molar distalization with Carriere distalizer appliance before and after second molar eruption.

Using CBCT to measure various skeletal and dental changes in the present study could offer the distinct advantage of one-toone geometry, and provide the potential for utilizing additional anatomical landmarks not detectable in the two-dimensional cephalograms. ${ }^{21,22}$ Moreover, distinct views could be obtained for both right and left sides, allowing to increase the efficiency of image utilization, by omitting the superimposition of structures that were unrelated to the required landmark determination, and three-dimensional measurements. ${ }^{22}$ The multi-planer reconstruction displays of CBCT views can offer more accurate determination of cephalometric landmarks than conventional lateral cephalograms. ${ }^{23}$ 
Accordingly, the aim of this study was to compare the outcomes of maxillary first molar distalization using the Carriere distalizer appliance before and after second molar eruption. The null hypothesis was that the results of maxillary first molar distalization - including three-dimensional maxillary first molar movements, anchorage loss, amount of Class II correction and treatment duration - were not affected whether maxillary second molar was erupted or not.

\section{MATERIAL AND METHODS}

This prospective study included two groups of patients indicated for maxillary first molar distalization (thirty patients for each group). In the first group (19 females and 11 males, mean age of $11.6 \pm 0.9$ years), the treatment was accomplished prior to the eruption of the maxillary second molar, with the follicles of the second molars placed directly toward the cervical third of the first molar root. In the second group (21 females and 9 males, mean age of $14.3 \pm 1.4$ years), distalization started when both maxillary first and second molars erupted.

Patients in both groups fulfilled the following inclusion criteria:

1. More than half-cusp bilateral Angle's Class II molar relation.

2. Skeletal Class I malocclusion, with ANB angle less than $4^{\circ}$ and YEN angle between $117^{\circ}$ and $123^{\circ} .24,25$ 
3. Total mandibular arch discrepancy, indicating that there was no need for extraction in the mandibular arch.

4. No pretreatment transverse discrepancy.

5. No previous orthodontic treatment.

The sample size was calculated according to the following formula:

$\mathrm{n}=\frac{2\left(Z_{\alpha}+Z_{[1-\beta]}\right)^{2} \times\left(\frac{S D_{1}{ }^{2}+S D_{2}{ }^{2}}{2}\right)}{D^{2}}$

In which $Z_{\alpha}=1.96$ for $\alpha$ of 0.05 (significance at $p<0.05$ ) and $Z_{[1-\beta]}=1.28$ for $\beta$ of 0.10 (the power of study is $90 \%$ ). Also, $S D_{1}$ and $\mathrm{SD}_{2}$ are the standard deviations of maxillary molar distalization for a pilot study of ten randomly selected patients in the first and the second groups, respectively. $D$ is the effect size (the minimal clinical relevant maxillary molar distalization difference between both groups in the pilot study).

So, $\mathrm{n}=\frac{2(1.96+1.28)^{2} \times\left(\frac{0.97^{2}+1.19^{2}}{2}\right)}{(0.91)^{2}}$

$\mathrm{n}=30$ patients per group. 
Effect of second molar eruption on efficiency of maxillary first molar distalization using Carriere distalizer appliance

Distalization was performed with the Carriere distalizer appliance for all patients (Figs 1 and 2). A 0.036-in lower lingual holding arch was soldered to bands cemented on the mandibular first molars, to provide anchorage for molar distalization. The mandibular arch was bonded for all patients by the same operator, using mini master brackets with 0.022-in slot size (American Orthodontics, Sheboygan, Wis) and leveled reaching $0.019 \times 0.025$-in stainless steel archwire. The distalizer was then bilaterally bonded by the same operator in all subjects.

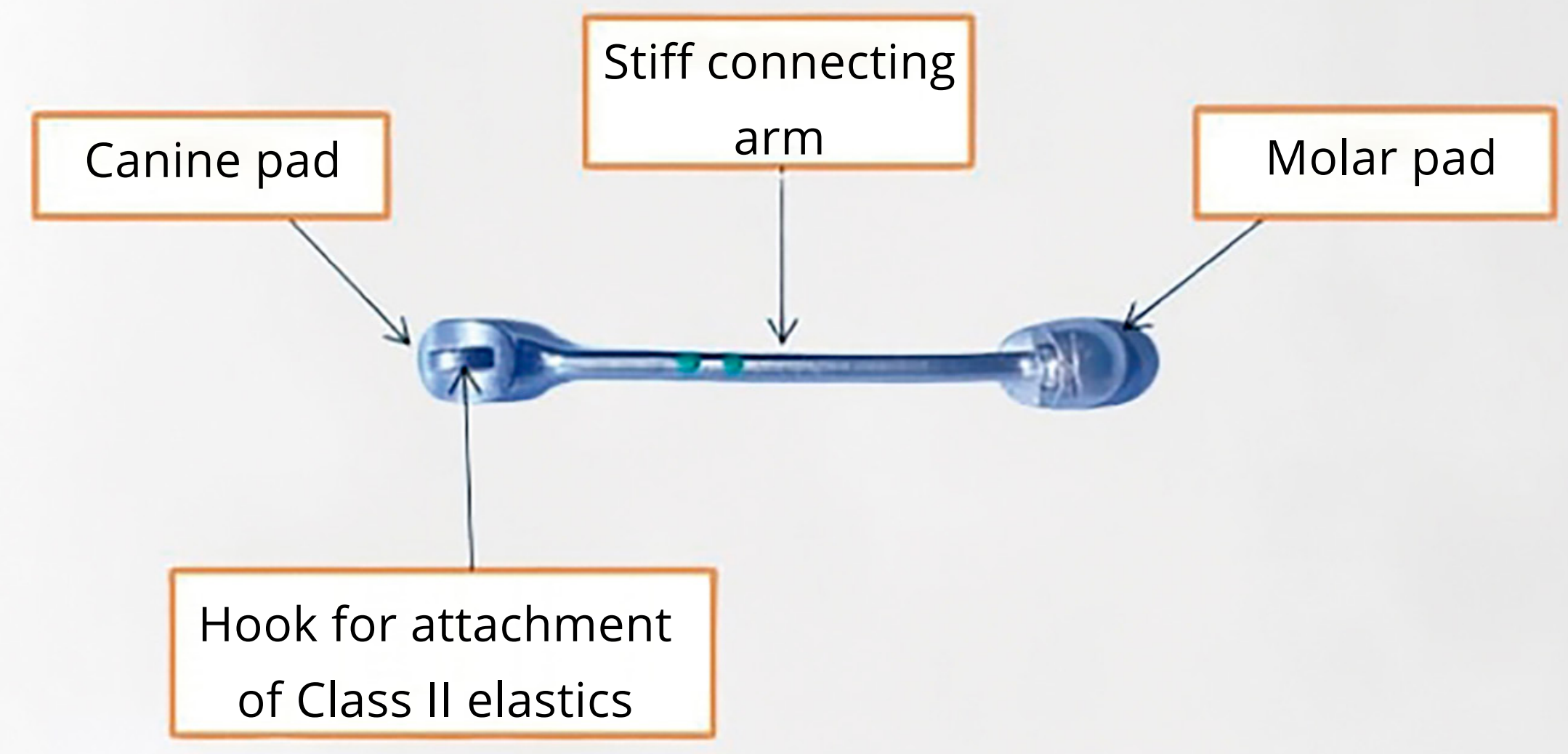

Figure 1: Design of the Carriere distalizer. 
Effect of second molar eruption on efficiency of maxillary first molar distalization using Carriere distalizer appliance

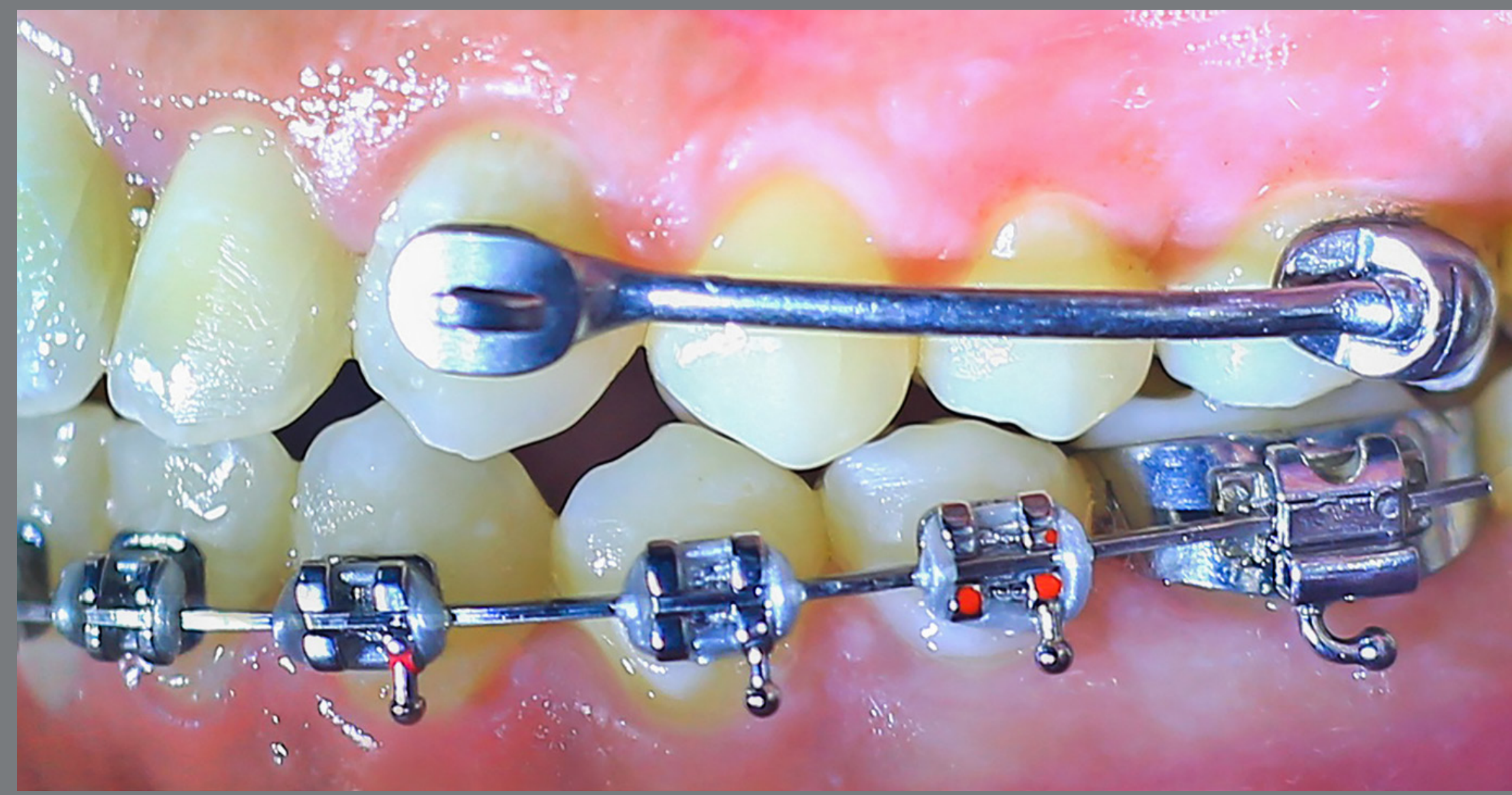

Figure 2: Bonded Carriere distalizer appliance.

All patients were instructed to use heavy Class II elastics with 1/4-in diameter (American Orthodontics, Sheboygan, Wis), attaching them from the mandibular molar band hook to the hook on maxillary cuspid pad of the distalizer. A force gauge (Dentaurum, Pforzheim, Germany) was used to measure the amount of force produced by Class II elastics once attached. Patients were instructed to wear the elastics all the time, except during eating or playing sports, and to change them after every meal. 
Every patient was instructed to fill-in a schedule, for self-reporting the duration of wearing Class II elastics every day. Follow-up visits were scheduled every two weeks, to report any problems and to check the compliance of the patients. Reports from parents were required to overcome the social desirability bias during filling-in the schedule. Patients were also instructed to fill in the report every hour, helped by memory aids to overcome the recall bias. ${ }^{26}$

One CBCT image (Scanora3D, Sorredex- Finland) was taken for each patient before distalization, and another one when a bilateral Class I molar relationship was attained, in the same standardized technique. Exposure was performed at $15 \mathrm{~mA}$ and $85 \mathrm{KV}$. The obtained CBCT images were transformed to DICOM format (Digital Imaging and Communications in Medicine) with the i-CAT software (Hatfield, Pennsylvania, USA). A fully reconstructed three-dimensional volumetric image was generated by utilizing the Mimics image processing software (Materialise Group, Leuven, Belgium).

The three-dimensional images were subsequently reoriented to the Frankfort horizontal reference plane. The sagittal reference plane was set perpendicular to the horizontal reference plane, and connecting the nasion and the right porion points. The frontal plane was extended from the nasion, and normal to the horizontal and sagittal planes. Identification of landmarks 
was determined by using the generated multiplanar projections. The selected points were then assessed in the three-dimensional image. Measurements were taken to compare both groups regarding the amounts of maxillary first molar distalization, mesiodistal tipping, bucccolingual torquing and rotation, in addition to anchorage loss and skeletal changes. Moreover, the treatment durations were compared. Figure 3 and Tables 1 , 2 and 3 show the landmarks, planes and measurements used in this study.

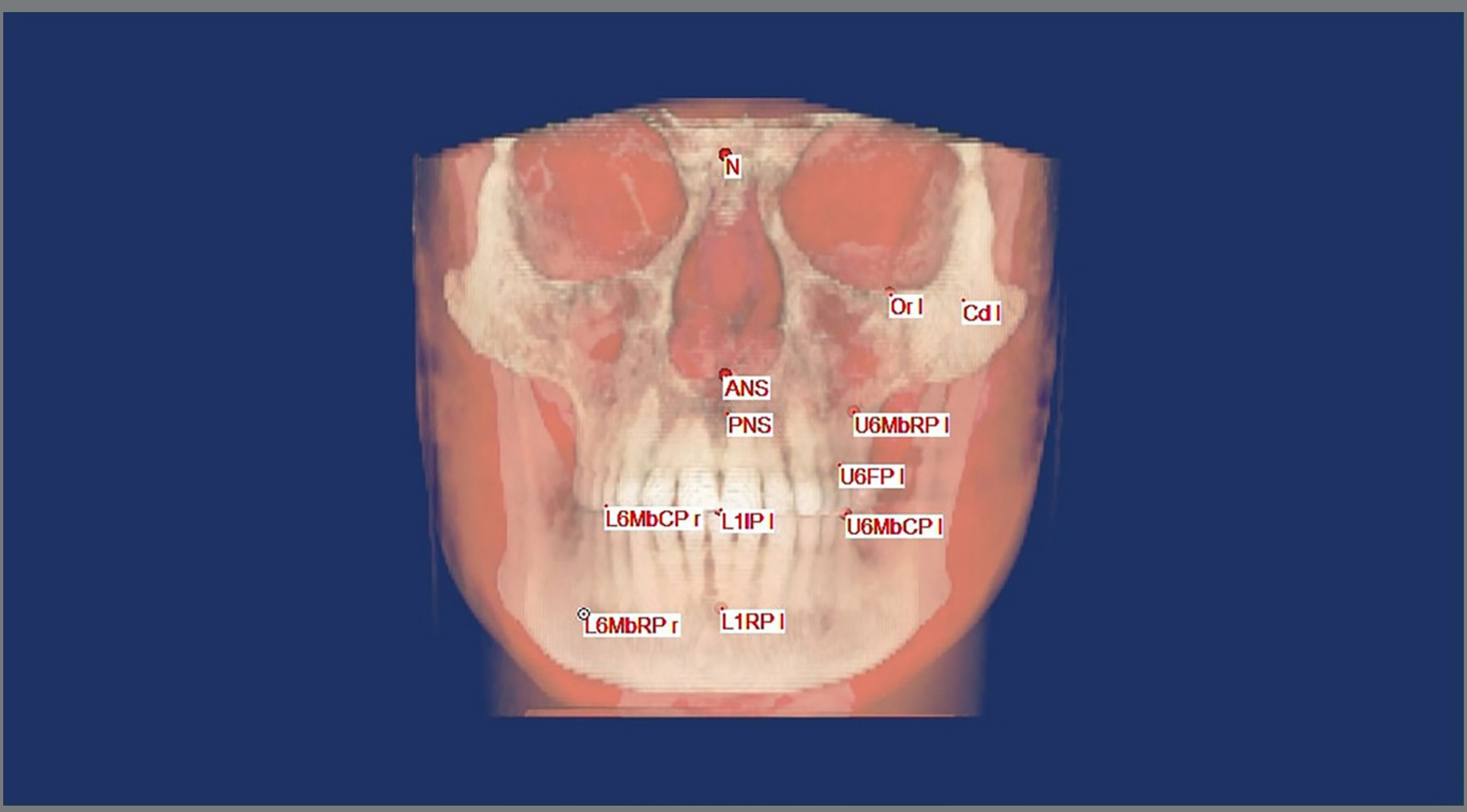

Figure 3: Determination of landmarks on the Mimics software. 
Table 1: Three-dimensional cephalometric reference landmarks.

\begin{tabular}{|c|c|}
\hline Point & Description \\
\hline S (Sella) & The midpoint of the sella turcica \\
\hline $\mathrm{N}$ (Nasion) & The most anterior point on the frontonasal suture \\
\hline A (Subspinale) & $\begin{array}{l}\text { The deepest midline point in the curved bony outline from } \\
\text { the base to the alveolar process of the maxilla }\end{array}$ \\
\hline B (Supramentale) & $\begin{array}{l}\text { The most posterior point in the outer contour of the mandib- } \\
\text { ular alveolar process in the median plane }\end{array}$ \\
\hline M point & $\begin{array}{c}\text { The center of the largest best fit circle tangent to anterior, } \\
\text { superior, and palatal surface of premaxilla (midpoint of the } \\
\text { premaxilla) }\end{array}$ \\
\hline G point & $\begin{array}{l}\text { The center of the largest best fit circle tangent to the internal, } \\
\text { anterior, inferior, and posterior surfaces of mandibular sym- } \\
\text { physis (center of mandibular symphysis) }\end{array}$ \\
\hline GnR (right gnathion) & $\begin{array}{l}\text { The point in the midway between the most anterior and the } \\
\text { most inferior points of the chin on the right side }\end{array}$ \\
\hline OrR - OrL (right and left orbitale) & The most inferior point on the orbital margin at both sides \\
\hline PoR (right porion) & $\begin{array}{c}\text { The highest point on the external auditory meatus on the } \\
\text { right side }\end{array}$ \\
\hline ANS (anterior nasal spine) & $\begin{array}{l}\text { The most anterior midpoint of the anterior nasal spine of the } \\
\text { maxilla }\end{array}$ \\
\hline PNS (posterior nasal spine) & $\begin{array}{l}\text { The most posterior midpoint of the posterior nasal spine of } \\
\text { the palatine bone }\end{array}$ \\
\hline CdR-CdL (right and left Condylion) & $\begin{array}{l}\text { The most superior point on the head of the condyle at both } \\
\text { sides }\end{array}$ \\
\hline $\begin{array}{l}\text { U6MbCPR - U6MbCPL (right and left maxillary first } \\
\text { molar mesiobuccal cusp tip) }\end{array}$ & $\begin{array}{l}\text { The tip of the mesiobuccal cusp of the right and left maxillary } \\
\text { first molar crowns }\end{array}$ \\
\hline $\begin{array}{l}\text { U6MbRPR - U6MbRPL (right and left maxillary first } \\
\text { molar mesiobuccal root apex) }\end{array}$ & $\begin{array}{l}\text { The apex of the mesiobuccal root of the right and left maxil- } \\
\text { lary first molars }\end{array}$ \\
\hline $\begin{array}{l}\text { U6DbCPR - U6DbCPL (right and left maxillary first } \\
\text { molar disto-buccal cusp tip) }\end{array}$ & $\begin{array}{c}\text { The tip of the distobuccal cusp of the right and left maxillary } \\
\text { first molar crowns }\end{array}$ \\
\hline $\begin{array}{l}\text { L6MbCPR - L6MbCPL (right and left mandibular first } \\
\text { molar mesiobuccal cusp tip) }\end{array}$ & $\begin{array}{l}\text { The tip of the mesiobuccal cusp of the right and left mandibu- } \\
\text { lar first molar crowns }\end{array}$ \\
\hline $\begin{array}{l}\text { U6FPR - U6FPL (right and left maxillary first molar } \\
\text { furcation point) }\end{array}$ & $\begin{array}{l}\text { The mid furcation point between the roots of the right and } \\
\text { left maxillary first molars }\end{array}$ \\
\hline $\begin{array}{l}\text { L6MbRPR - L6MbRPL (right and left mandibular first } \\
\text { molar mesiobuccal root apex) }\end{array}$ & $\begin{array}{c}\text { The apex of the mesiobuccal root of the right and left man- } \\
\text { dibular first molars }\end{array}$ \\
\hline
\end{tabular}

L1IPR - L1IPL (right and left mandibular central incisor incisal point)

L1RPR - L1RPL (right and left mandibular central incisor root point)

The tip of the incisal edge of each mandibular central incisor

The apex of the root of each mandibular central incisor 
Table 2: Three-dimensional cephalometric reference lines and planes.

\section{Line or plane \\ Description}

FHP (Frankfurt horizontal plane)

VP (Vertical plane)

MxS (Maxillary sagittal line)

FL (Frontal line)

U6 long axis

L6 long axis

L1 long axis

The plane passing through OrR, OrL and PoR points

The plane passing through $\mathrm{CdR}$ and $\mathrm{CdL}$ and perpendicular to the FHP

The line connecting ANS and PNS

The line connecting OrR and OrL

The line connecting U6MbCP and U6MbRP

The line connecting L6MbCP and L6MbRP

The line connecting L1IP and L1RP

\section{Table 3: Three-dimensional CBCT measurements.}

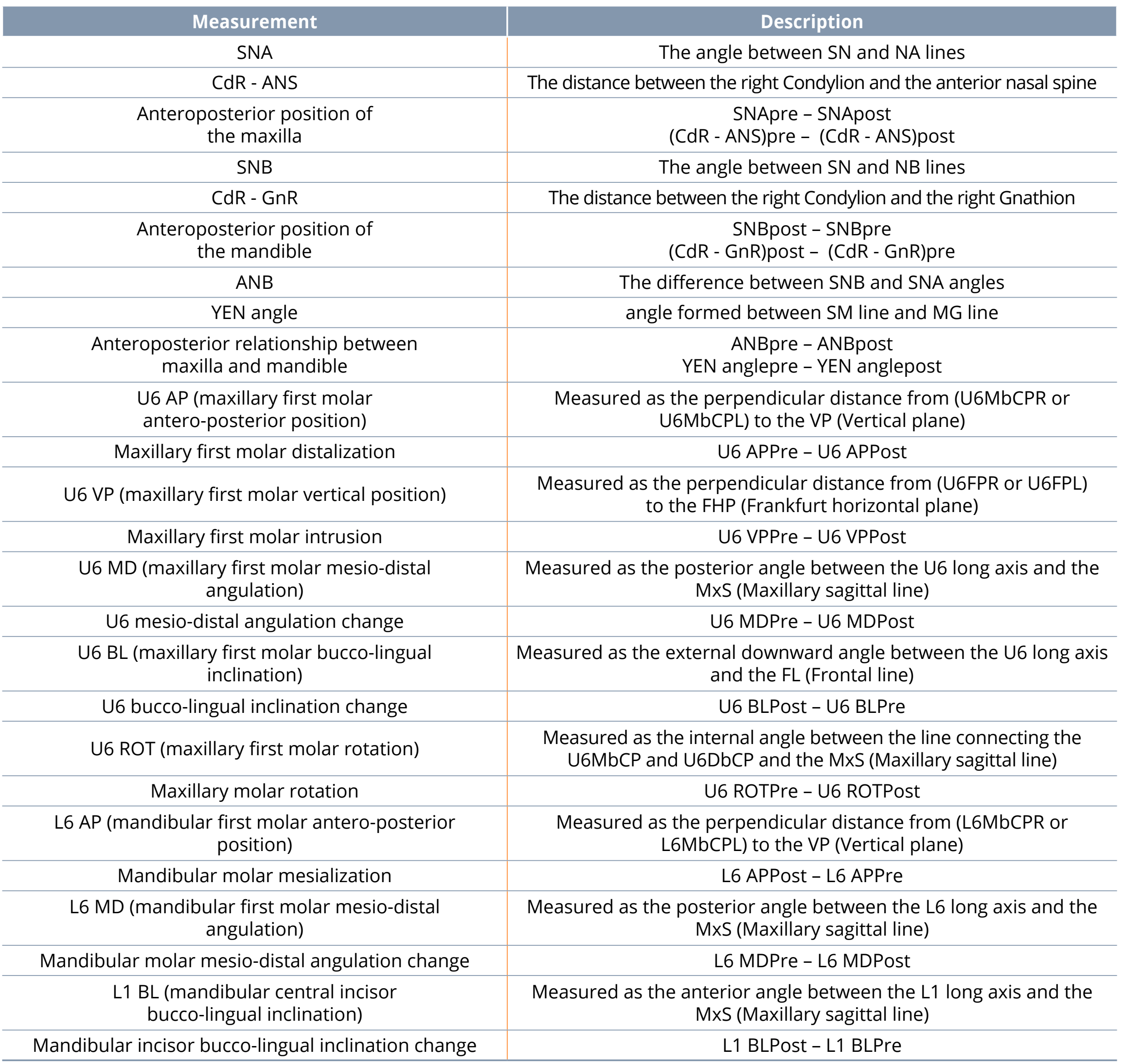


Before starting distalization in both groups, the severity of the Class II molar relationship was measured as the horizontal distance between the mesiobuccal cusp tips of maxillary and mandibular first molars, and compared in both groups. The distance zero indicated a half-cusp Class II molar relationship. As the distance increased, the severity of Class II relationship increased. Complementarily, the skeletal relationship was compared between both groups. Independent $t$-test revealed no significant differences between both groups in all these pretreatment variables (pretreatment Class II severity was $2.5 \pm 0.8 \mathrm{~mm}$ and $2.2 \pm 0.9 \mathrm{~mm}$, respectively, with $p$-value $=0.201$; ANB angle was $2.8 \pm 0.5^{\circ}$ and $2.9 \pm 0.8^{\circ}$, respectively, with $p$-value $=0.471$; and YEN angle was $120.1 \pm 2^{\circ}$ and $119.7 \pm 1.7^{\circ}$, respectively, with $p$-value $=0.352$.

In all patients of both groups, bilateral Class I molar relationship was achieved. All patients in both groups properly tolerated the appliance. No distalizer debonding occurred in any subject from any group during the treatment period.

\section{STATISTICAL METHOD}

The collected data were statistically analyzed using SPSS (Statistical Package for Social Sciences) software (version 9.0, SPSS, Chicago, USA). Descriptive statistics were done (means and standard deviations) for all variables included in the study. 
All variables were subjected to Shapiro-Wilk test, which revealed normal distribution for all of them ( $p>0.05$ for all variables). Analyses between both groups for parametric quantitative data were done using independent samples $t$-test, and for qualitative data, using Chi-square test (expected number per cell $>5$ ). The level of significance was defined at $p$ value $<0.05$.

Correlations between pretreatment Class II severity and other variables were analyzed using Pearson's correlation coefficient. Differences with less than 5\% probabilities were considered statistically significant.

\section{ERROR OF THE METHOD}

All reference landmarks, planes and measurements were relocated and measured again by three different operators. Reliability of measurements was estimated by Cronbach's Alpha and Inter-Class Correlation.

\section{RESULTS}

The method reliability was excellent, with Cronbach's Alpha and Inter-Class Correlation of more than 0.9 for all measurements in both groups (Table 4). For all variables included in the study, no significant differences were found between boys and girls in both groups (Table 5). Accordingly, for both groups, the results for both boys and girls were analyzed together. 
Table 4: Estimation of the reliability of measurements in both groups, by Cronbach's Alpha and Inter-Class Correlation.

\begin{tabular}{|c|c|c|c|c|c|c|}
\hline & \multicolumn{3}{|c|}{ Group II } & \multicolumn{3}{|c|}{ Group I } \\
\hline & \multirow{2}{*}{$\begin{array}{l}\text { Cronbach's } \\
\text { Alpha }\end{array}$} & \multicolumn{2}{|c|}{ Interclass correlation } & \multirow{2}{*}{$\begin{array}{l}\text { Cronbach's } \\
\text { Alpha }\end{array}$} & \multicolumn{2}{|c|}{ Interclass correlation } \\
\hline & & $\mathbf{R}$ & P value & & $\mathbf{R}$ & P value \\
\hline U 6 AP & 0.999 & 0.998 & $<0.001 *$ & 0.999 & 0.996 & $<0.001 *$ \\
\hline $\begin{array}{c}\text { Pre-treatment Class II sever- } \\
\text { ity }\end{array}$ & 0.999 & 0.998 & $<0.001 *$ & 0.998 & 0.993 & $<0.001$ * \\
\hline U $6 \mathrm{VP}$ & 0.998 & 0.993 & $<0.001 *$ & 0.999 & 0.996 & $<0.001 *$ \\
\hline U $6 \mathrm{MD}$ & 0.999 & 0.998 & $<0.001 *$ & 1 & 0.999 & $<0.001$ * \\
\hline U $6 \mathrm{BL}$ & 1 & 0.999 & $<0.001 *$ & 1 & 0.999 & $<0.001$ * \\
\hline U 6 ROT & 0.998 & 0.993 & $<0.001 *$ & 0.999 & 0.998 & $<0.001 *$ \\
\hline L 6 AP & 0.999 & 0.996 & $<0.001 *$ & 0.998 & 0.993 & $<0.001 *$ \\
\hline L $6 \mathrm{MD}$ & 1 & 0.999 & $<0.001 *$ & 0.999 & 0.996 & $<0.001 *$ \\
\hline $\mathrm{L} 1 \mathrm{BL}$ & 0.998 & 0.993 & $<0.001 *$ & 1 & 0.999 & $<0.001$ * \\
\hline SNA & 0.999 & 0.998 & $<0.001 *$ & 0.998 & 0.993 & $<0.001 *$ \\
\hline CdR - ANS & 0.988 & 0.964 & $<0.001 *$ & 0.998 & 0.994 & $<0.001$ * \\
\hline SNB & 0.998 & 0.994 & $<0.001 *$ & 1 & 0.999 & $<0.001$ * \\
\hline CdR - GnR & 0.999 & 0.998 & $<0.001 *$ & 0.999 & 0998 & $<0.001$ * \\
\hline ANB & 0.998 & 0.994 & $<0.001 *$ & 0.998 & 0.993 & $<0.001 *$ \\
\hline YEN angle & 1 & 0.999 & $<0.001 *$ & 0.999 & 0.998 & $<0.001$ * \\
\hline
\end{tabular}

*: Significant level at $\mathrm{P}$ value $<0.05$.

No significant difference $(p=0.252)$ was found in the mean duration of elastics wear per day between both groups (19.8 \pm 2 and $20.9 \pm 1.5$ hours per day, respectively). Also, no significant difference was found ( $p=0.32$ ) in the amount of force produced by Class II elastics between both groups (194 $\pm 26 \mathrm{~g}$ and $201 \pm 31$ g, respectively).

The mean first molar distalization period in the first group was $19.2 \pm 1.6$ weeks. It was significantly smaller $(p=0.001)$ than the mean distalization period in the second group, which was 
Table 5: Difference between boys and girls, for both groups.

\begin{tabular}{|c|c|c|c|c|c|c}
\hline & \multicolumn{3}{|c|}{ Group I } & \multicolumn{3}{c}{ Group II } \\
\hline & Males & Females & P value & Males & Females & P value \\
\hline Pretreatment Class Il severity & $2.9 \pm 0.9$ & $2.3 \pm 0.7$ & 0.127 & $2.3 \pm 1.1$ & $2 \pm 0.5$ & 0.558 \\
\hline U 6 AP & $4.2 \pm 0.8$ & $3.8 \pm 0.8$ & 0.301 & $3.3 \pm 0.6$ & $2.7 \pm 0.6$ & 0.078 \\
\hline Percent of first molar movement & $70.2 \pm 14.1$ & $65.7 \pm 16.6$ & 0.952 & $62.2 \pm 11.4$ & $53.8 \pm 14.3$ & 0.209 \\
\hline U 6 VP & $1.3 \pm 0.9$ & $0.9 \pm 0.8$ & 0.874 & $1.6 \pm 0.8$ & $1.3 \pm 0.8$ & 0.634 \\
\hline U 6 MD & $5 \pm 1.5$ & $5.5 \pm 0.9$ & 0.440 & $4.8 \pm 1.2$ & $4.9 \pm 1.6$ & 0.917 \\
\hline U 6 BL & $3 \pm 1.1$ & $2.9 \pm 0.9$ & 0.367 & $2.9 \pm 0.9$ & $3.3 \pm 0.8$ & 0.905 \\
\hline U 6 ROT & $5.6 \pm 1.4$ & $5.5 \pm 0.7$ & 0.353 & $6.9 \pm 1$ & $7.4 \pm 1.2$ & 0.800 \\
\hline L 6 AP & $1 \pm 0.8$ & $1.2 \pm 0.9$ & 0.958 & $2.1 \pm 0.9$ & $1.8 \pm 0.7$ & 0.491 \\
\hline L 6 MD & $3 \pm 0.7$ & $3.4 \pm 1.7$ & 0.233 & $4.3 \pm 1.2$ & $5.2 \pm 1.3$ & 0.536 \\
\hline L 1 BL & $4.7 \pm 1.2$ & $5 \pm 1.9$ & 0.526 & $6.6 \pm 0.9$ & $6.9 \pm 1.3$ & 0.634 \\
\hline SNA & $0.7 \pm 0.3$ & $0.9 \pm 0.4$ & 0.711 & $0.8 \pm 0.4$ & $0.9 \pm 0.3$ & 0.916 \\
\hline CdR - ANS & $0.7 \pm 0.4$ & $1 \pm 0.5$ & 0.634 & $1.1 \pm 0.4$ & $1.4 \pm 0.6$ & 0.874 \\
\hline SNB & $1 \pm 0.4$ & $0.8 \pm 0.3$ & 0.204 & $0.8 \pm 0.3$ & $1 \pm 0.5$ & 0.427 \\
\hline CdR - GnR & $3.8 \pm 1.2$ & $3.5 \pm 1.1$ & 0.543 & $4.1 \pm 0.7$ & $4.1 \pm 1$ & 0.899 \\
\hline ANB & $1.8 \pm 0.4$ & $1.5 \pm 0.4$ & 0.143 & $1.6 \pm 0.3$ & $1.9 \pm 0.4$ & 0.175 \\
\hline YEN angle & $4.9 \pm 1.1$ & $4.9 \pm 1.3$ & 0.988 & $5.4 \pm 0.8$ & $5.5 \pm 1.6$ & 0.904 \\
\hline Elastics wearing time (hours/ day) & $19.6 \pm 1.3$ & $20 \pm 1.3$ & 0.544 & $20.9 \pm 1.2$ & $21 \pm 0.9$ & 0.816 \\
\hline Treatment Duration (weeks) & $18.7 \pm 2$ & $19.3 \pm 1.6$ & 0.542 & $23.5 \pm 1.4$ & $22.9 \pm 1.6$ & 0.404 \\
\hline
\end{tabular}

Quantitative data expressed as mean \pm SD.

Chi square test for qualitative data between both groups.

Independent samples $t$-test for quantitative data between both groups.

Significant level at $p$-value $<0.05$.

$23.3 \pm 2.3$ weeks. No significant differences between both groups were observed in all skeletal measurements. No significant correlations between the pretreatment Class II severity and other variables included in the study were observed (Table 6).

Maxillary first molar distalization constituted $67.4 \pm 15.1 \%$ from the total Class II correction in the first group, which was significantly greater than in the second group, that was $58.5 \pm 13 \%(p=0.022)$. 
Table 6: Correlation between the pretreatment Class II severity and other variables included in the study, in both groups.

\begin{tabular}{|c|c|c|c|c|}
\hline & \multicolumn{2}{|c|}{ Group I } & \multicolumn{2}{|c|}{ Group II } \\
\hline & $r$ & $P$ value & $\mathbf{r}$ & $P$ value \\
\hline U 6 AP & 0.403 & 0.121 & 0.409 & 0.116 \\
\hline U 6 VP & -0.137 & 0.614 & 0.030 & 0.911 \\
\hline U $6 \mathrm{MD}$ & 0.0 & 1 & 0.166 & 0.540 \\
\hline U 6 BL & -0.007 & 0.979 & 0.029 & 0.915 \\
\hline U 6 ROT & 0.083 & 0.761 & -0.031 & 0.910 \\
\hline L 6 AP & 0.068 & 0.803 & -0.301 & 0.257 \\
\hline L $6 \mathrm{MD}$ & -0.087 & 0.748 & 0.240 & 0.370 \\
\hline $\mathrm{L} 1 \mathrm{BL}$ & -0.242 & 0.367 & 0.171 & 0.527 \\
\hline SNA & -0.026 & 0.924 & -0.467 & 0.068 \\
\hline CdR - ANS & -0.133 & 0.624 & -0.117 & 0.667 \\
\hline SNB & 0.081 & 0.765 & 0.140 & 0.604 \\
\hline CdR - GnR & 0.345 & 0.191 & 0.247 & 0.356 \\
\hline ANB & -0.334 & 0.207 & 0.335 & 0.204 \\
\hline YEN angle & -0.124 & 0.648 & -0.108 & 0.690 \\
\hline Elastics wearing time (hours/ day) & 0.076 & 0.780 & 0.149 & 0.582 \\
\hline Treatment duration (weeks) & -0.031 & 0.908 & 0.046 & 0.866 \\
\hline
\end{tabular}

Pearson's correlation.

*: Significant level at $\mathrm{P}$ value $<0.05$.

The amount of maxillary first molar distalization was significantly greater $(p=0.001)$ in the first than the second group ( $3.9 \pm 0.8$ and $3 \pm 0.6 \mathrm{~mm}$, respectively). No statistically significant differences were found between both groups regarding the quantities of maxillary first molar intrusion, mesiodistal tipping and buccolingual torquing.

Regarding maxillary first molar rotation, distalizing both first and second molars together resulted in more significant first molar rotation than distalizing the first molar alone $(p<0.001)$. 


\section{The mandibular incisor labiolingual torquing and the man- dibular first molar mesialization and mesiodistal tipping were significantly increased in the second group, indicating more anchorage loss. All these results are summarized in Table 7.}

Table 7: Changes in three-dimensional cephalometric measurements, elastics wearing time and treatment duration after maxillary first molar distalization, in both groups.

\begin{tabular}{|c|c|c|c|}
\hline & Group I & Group II & $P$ value \\
\hline Sex & $\begin{array}{cc}\text { Male } & 11(36.67 \%) \\
\text { Female } & 19(63.33 \%)\end{array}$ & $\begin{array}{cl}\text { Male } & 9(30 \%) \\
\text { Female } & 21(70 \%)\end{array}$ & 0.480 \\
\hline Pretreatment Class II severity & $2.5 \pm 0.8$ & $2.2 \pm 0.9$ & 0.201 \\
\hline U 6 AP & $3.9 \pm 0.8$ & $3 \pm 0.6$ & $0.001 *$ \\
\hline Percent of first molar movement & $67.4 \pm 15.1$ & $58.5 \pm 13$ & $0.022 *$ \\
\hline U 6 VP & $1.2 \pm 0.8$ & $1.5 \pm 0.7$ & 0.323 \\
\hline U $6 \mathrm{MD}$ & $5.2 \pm 1.2$ & $4.9 \pm 1.4$ & 0.402 \\
\hline U $6 \mathrm{BL}$ & $3 \pm 1$ & $3.1 \pm 0.8$ & 0.605 \\
\hline U 6 ROT & $5.6 \pm 1.1$ & $7.2 \pm 1.1$ & $<0.001 *$ \\
\hline L 6 AP & $1.1 \pm 0.7$ & $2 \pm 0.8$ & $0.004^{*}$ \\
\hline L $6 \mathrm{MD}$ & $3.2 \pm 1.2$ & $4.8 \pm 1.3$ & $0.001 *$ \\
\hline $\mathrm{L} 1 \mathrm{BL}$ & $4.8 \pm 1.5$ & $6.7 \pm 1.1$ & $<0.001 *$ \\
\hline SNA & $0.8 \pm 0.5$ & $0.8 \pm 0.4$ & 0.692 \\
\hline CdR - ANS & $0.9 \pm 0.4$ & $1.3 \pm 0.5$ & 0.250 \\
\hline SNB & $0.9 \pm 0.4$ & $0.9 \pm 0.5$ & 0.763 \\
\hline CdR - GnR & $3.6 \pm 1.1$ & $4.1 \pm 0.8$ & 0.195 \\
\hline ANB & $1.7 \pm 0.4$ & $1.8 \pm 0.4$ & 0.519 \\
\hline YEN angle & $4.9 \pm 1.2$ & $5.4 \pm 1.2$ & 0.212 \\
\hline Elastics wearing time (hours/ day) & $19.8 \pm 2$ & $20.9 \pm 1.5$ & 0.252 \\
\hline Treatment Duration (weeks) & $19.2 \pm 1.6$ & $23.3 \pm 2.3$ & $0.001 *$ \\
\hline
\end{tabular}

Quantitative data expressed as mean \pm SD while qualitative data expressed by frequency and percentage.

Chi-square test for qualitative data between both groups.

Independent samples $t$-test for quantitative data between the two groups.

* Significant level at $p$-value $<0.05$. 


\section{DISCUSSION}

Attaining a Class I molar relationship is a fundamental component of appropriate balanced occlusion and facial esthetics. ${ }^{27}$ There are controversies regarding the influence of second molar eruption upon various aspects of maxillary first molar distalization. The results of this study did not show any statistically significant differences in different skeletal measurements whether second molar had erupted or not.

The treatment time was significantly shorter, the quantity of maxillary first molar distalization was significantly larger and the amount of rotation was significantly smaller in the group with unerupted maxillary second molar. The differences between both groups were not significant regarding the amount of first molar buccolingual torquing.

Also, the amount of anchorage loss (indicated by mandibular first molar mesial migration and mandibular incisor labiolingual inclination) was significantly greater when the second molar was erupted.

The main outcomes of this study corroborate the results of two lateral cephalometric studies utilizing intra-arch NiTi coil spring with Nance appliance ${ }^{15}$ and molar distalizing bow. ${ }^{28}$ This approach is efficient to distalize maxillary first molar prior to second molar eruption, attaining the advantages of 
more efficient first molar distalization and less anchorage loss. Continuing maxillary first molar distalization following maxillary second molar eruption slows down the rate of distalization, that becomes equivalent to starting first molar distalization after second molar eruption. ${ }^{17}$

However, according to two other studies using the XBow appliance $^{13}$ and the Pendulum appliance, ${ }^{29}$ lateral cephalometric measurements did not show significant differences in the quantity of maxillary first molar distalization and anchorage loss whether the second molar was erupted or not, suggesting that second molar eruption has negligible influence on first molar distalization.

Also, the results of this study support the concept that it is more hazardous to the anchorage if both first and second molars are distalized together, as combined teeth have larger root surface area than a single tooth. Anchorage is less compromised when the first molar is distalized before second molar eruption, resulting in less time-consuming correction of the anchorage loss. ${ }^{15}$ 
However, mesiodistal tipping of the first molar was not significantly changed in this study, whether distalized before or after second molar eruption. These findings agree with the results of a lateral cephalometric study using the XBow appliance, which concluded that there was no difference in the mesiodistal tipping change of the distalized maxillary first molar whether the second molar was present or unerupted. ${ }^{13}$

This evidence does not agree with the idea that the unerupted second molar would probably impact distal tipping of the first molar to a considerable degree, ${ }^{14}$ resulting in more significant first molar mesiodistal tipping than when the second molar is present. ${ }^{5}$ Both studies utilized two-dimensional lateral cephalograms to assess alterations in the position of the maxillary first molar. ${ }^{5,14}$

Concerning maxillary first molar buccolingual torquing, this study suggests no significant difference whether the first molar is distalized before or after second molar eruption. According a three-dimensional finite element analysis by Kang et al.,, 30 it was more effective to utilize a bone-anchored pendulum appliance to distalize maxillary first molar before second molar eruption, as this resulted in less first molar buccal tipping. 
According to the results of this study, if the operator has the choice to distalize maxillary first molars with the Carriere distalizer appliance before or after second molar eruption, earlier initiation of the treatment is more favorable.

As maxillary first molars in all subjects included in this study were distalized with Carriere distalizer appliance, outcomes of this study can be considered precise for patients treated with this distalizer only.

In this study, randomization of patients between both groups implicates that all subjects should have unerupted second molars, starting treatment immediately in the first group and waiting for second molar eruption in the second group. As delaying the treatment was not ethical for the second group, subjects were selected in both groups by a single operator depending on the predetermined selection criteria, except that second molars had already erupted in one group.

\section{CONCLUSION}

Maxillary first molar distalization using Carriere distalizer appliance before maxillary second molar eruption is more efficient, less time-consuming and more anchorage-conserving than after second molar eruption. 


\section{REFERENCES}

1. Janson G, Maria FRT, Barros SEC, Freitas MR, Henriques JFC. Orthodontic treatment time in 2- and 4-premolar-extraction protocols. Am J Orthod Dentofacial Orthop. 2006 May;129(5):666-71.

2. Vaden JL, Williams RA, Goforth RL. Class II correction: Extraction or nonextraction? Am J Orthod Dentofacial Orthop. 2018 Dec;154(6):860-876.

3. Ellen EK, Schneider BJ, Sellke T. A comparative study of anchorage in bioprogressive versus standard edgewise treatment in Class II correction with intermaxillary elastic force. Am J Orthod Dentofacial Orthop. 1998 Oct;114(4):430-6.

4. Byloff FK, Darendeliler MA. Distal molar movement using the pendulum appliance. Part 1: Clinical and radiological evaluation. Angle Orthod. 1997;67(4):249-60.

5. Bolla E, Muratore F, Carano A, Bowman SJ. Evaluation of maxillary molar distalization with the distal jet: a comparison with other contemporary methods. Angle Orthod. 2002 Oct;72(5):481-94.

6. Li M, Su X, Li Y, Li X, Si X. Cone-beam computed tomography-guided three-dimensional evaluation of treatment effectiveness of the Frog appliance. Korean J Orthod. 2019 May;49(3):161-169.

7. Kang SJ, Kim HH, Hwang HS, Lee KM. Immediate changes in the mandibular dentition after maxillary molar distalization using headgear. Korean J Orthod. 2017 Mar;47(2):142-147. 
8. Lee SK, Abbas NH, Bayome M, Baik UB, Kook YA, Hong M, et al. A comparison of treatment effects of total arch distalization using modified C-palatal plate vs buccal miniscrews. Angle Orthod. 2018 Jan;88(1):45-51.

9. Carrière L. A new Class II distalizer. J Clin Orthod. 2004 Apr;38(4):22431.

10. McFarlane B. Class II correction prior to orthodontics with the carriere distalizer. Int J Orthod Milwaukee. 2013 Fall;24(3):35-6.

11. Yin K, Han E, Guo J, Yasumura T, Grauer D, Sameshima G. Evaluating the treatment effectiveness and efficiency of Carriere Distalizer: a cephalometric and study model comparison of Class II appliances. Prog Orthod. 2019 Jun;20(1):24.

12. Kim-Berman $H$, McNamara Jr JA, Lints JP, McMullen C, Franchi L. Treatment effects of the Carriere ${ }^{\circledR}$ Motion 3D ${ }^{\mathrm{TM}}$ appliance for the correction of Class II malocclusion in adolescents. Angle Orthod. 2019 Nov;89(6):839-846.

13. Flores-Mir C, McGrath LM, Heo G, Major PW. Efficiency of molar distalization with the XBow appliance related to second molar eruption stage. Eur J Orthod. 2013 Dec;35(6):745-51.

14. Kinzinger GSM, Fritz UB, Sander FG, Diedrich PR. Efficiency of a pendulum appliance for molar distalization related to second and third molar eruption stage. Am J Orthod Dentofacial Orthop. 2004 Jan;125(1):8-23.

15. Karlsson I, Bondemark L. Intraoral maxillary molar distalization. Angle Orthod. 2006 Nov; 76(6):923-9. 
16. Gianelly AA, Vaitas AS, Thomas WM, Berger DG. Distalization of molars with repelling magnets. J Clin Orthod. 1988 Jan;22(1):40-4.

17. Shpack N, Brosh T, Mazor Y, Shapinko Y, Davidovitch M, Sarig R, et al. Long- and short-term effects of headgear traction with and without the maxillary second molars. Am J Orthod Dentofacial Orthop. 2014 Oct;146(4):467-76.

18. Muse DS, Fillman MJ, Emmerson WJ, Mitchell RD. Molar and incisor changes with Wilson rapid molar distalization. Am J Orthod Dentofacial Orthop. 1993 Dec;104(6):556-65.

19. Flores-Mir C, McGrath L, Heo G, Major PW. Efficiency of molar distalization associated with second and third molar eruption stage. Angle Orthod. 2013 Jul;83(4):735-42.

20. Kapila SD, Nervina JM. CBCT in orthodontics: assessment of treatment outcomes and indications for its use. Dentomaxillofac Radiol. 2015;44(1):20140282.

21. Mah JK, Huang JC, Choo H. Practical applications of cone-beam computed tomography in orthodontics. J Am Dent Assoc. 2010 Oct;141 Suppl 3:7S-13S.

22. Larson BE. Cone-beam computed tomography is the imaging technique of choice for comprehensive orthodontic assessment. Am J Orthod Dentofacial Orthop. 2012 Apr;141(4):402, 404, 406 passim.

23. Ludlow JB, Gubler M, Cevidanes L, Mol A. Precision of cephalometric landmark identification: cone-beam computed tomography vs conventional cephalometric views. Am J Orthod Dentofacial Orthop. 2009 Sep;136(3):312.e1-10; discussion 312-3. 
24. Neela PK, Mascarenhas R, Husain A. A new sagittal dysplasia indicator: the YEN angle. World J Orthod. 2009 Summer;10(2):147-51.

25. Shetty S, Husain A, Majithia P, Uddin S. YEN-Linear: A sagittal cephalometric parameter. J World Fed Orthod. 2013 May;2(2):e57e60.

26. Althubaiti A. Information bias in health research: definition, pitfalls, and adjustment methods. J Multidiscip Healthc. 2016 May; 9:211-7.

27. Marure PS, Patil RU, Reddy S, Prakash A, Kshetrimayum N, Shukla $\mathrm{R}$. The effectiveness of pendulum, K-loop, and distal jet distalization techniques in growing children and its effects on anchor unit: A comparative study. J Indian Soc Pedod Prev Dent. 2016 OctDec;34(4):331-40.

28. Jeckel N, Rakosi T. Molar distalization by intra-oral force application. Eur J Orthod. 1991 Feb;13(1):43-6.

29. Ghosh J, Nanda RS. Evaluation of an intraoral maxillary molar distalization technique. Am J Orthod Dentofacial Orthop. 1996 Dec;110(6):639-46.

30. Kang JM, Park JH, Bayome M, Oh M, Park CO, Kook YA, et al. A threedimensional finite element analysis of molar distalization with a palatal plate, pendulum, and headgear according to molar eruption stage. Korean J Orthod. 2016 Sep;46(5):290-300. 